\title{
Effect of Psychological Capital and Emotional Intelligence on Employee's Job Performance
}

\author{
IMRAN SAEED \\ IBMS, University of Agriculture, Peshawar \\ SAIF ULLAH KHAN \\ Institute of Management Studies \\ University of Peshawar \\ GHAYYUR QADIR \\ Institute of Business Studies and Leadership \\ Abdul Wali Khan University, Mardan \\ ghayyurqadir@awkum.edu.pk \\ QANDEEL KHATTAK \\ IBMS, University of Agriculture, Peshawar
}

\begin{abstract}
Employee's job performance is considered to be very key variable effecting organizational performance. In today's hypercompetitive world global economy business need to try identifying the factors that has effect on employee's performance, and psychological capital and emotional intelligence are amongst them. Consequently the main aim of the study was to find out the relationship of psychological capital and emotional intelligence on employee's job performance in Public sector Universities of Peshawar. In order to obtain the required objectives, a sample of 170 respondents was selected randomly through proportional allocation method. Well-structured questionnaire was used to collect the data. For checking the reliability of data, Cronbach's alpha coefficient was used. The results quantified that the collected data is reliable as coefficient of Cronbach's alpha is greater than 0.70 for psychological capital and emotional intelligence. For employee performance the reliability measures was less than 70\%.MAS were greater than 3 for most of studied attributes showing that employees are in favor of effect of psychological capital and emotional intelligence on employee's performance. The results of Chi-square showed a significant $(P<0.05)$ association between psychological capital and employee performance and also emotional intelligence and employee performance. Grounded on the results, it is determined that psychological capital and emotional intelligence are significantly associated with employee's performance.
\end{abstract}

Key words: Psychological capital, Emotional intelligence, employee performance

\section{Introduction}

The vital and prime need for the finest performance of the employees is the principal aim of each and every organization. It is also required from the organizations 
that they should achieve their objectives and basic aims and intents by making its employees work hard and also struggle for the success of firm to which they belong. Every single organization of any kind aims at achieving the best performance from its employees, excelling, getting superior position and standing out to be the best among the pool of competitors. Getting a deep insight to study the performance of employees in relation to different types and a variety of factors that have influencing effect on it has been the pivotal aim of vast degree of research. Additionally studies has made obvious that at workplace a range of variables can have an influence on the level of performance of employees and psychological capital and emotional intelligence are one of them.

Positive organizational behavior POB is defined as "the study and practice of positively oriented HR strong suit and psychological capabilities that can be measured, established, and managed effectively for performance enhancement" (Luthans, 2002b; Nelson and Cooper, 2007; Turner, et al. 2002; Wright, 2003). In order to distinguish from other positive approaches that are explained in the academic as well as the practitioner literatures, a set of criteria was set for including constructs in this definition of positive organizational behavior (Luthans, 2002a, b; Luthans et al., 2007) which includes the following points (1) grounded in theory as well as research; (2) appropriate i.e. valid measurement; (3) comparatively distinctive to the field of OB; (4) state-like which means open to improvement and development contrary to trait-like and so, relatively fixed; and (5) having a positive impression on sustainable performance (Luthans, 2002a,b; Luthans and Youssef, 2004; Luthans, et al. in press) and using this set of criteria, the positive psychological constructs which are determined to match the inclusion criteria to date include hope, optimism, resilience and self-efficacy and when these 4 terms are combined, represent psychological capital or PsyCap(Luthans and Youssef, 2004; Luthans et al. 2007).

Psychological capital or simply PsyCap is one of the facets or a derivative of positive organizational behavior (POB). The conceptual identification of psychological capital has been done by Luthans and his colleagues (Luthans, 2002; Luthans and Youssef, 2004; Luthans, et al. 2007). Formally psychological capital is defined as the positive psychological state of the individual's development which is characterized by: (1) (self-efficacy) i.e. having faith, belief or confidence to undertake and put forward the required effort to succeed while faced with challenging tasks; (2) (optimism) i.e. building of positive attribution about getting success now and in the further; (3) (hope) determined towards the goals and when required readdressing paths to goals so as to succeed; and (4) (resilience) when plagued by teething troubles and hardship, sustaining, bouncing back and even beyond to conquer and obtain success" (Luthans et al. 2007). When the above mentioned four core construct combine they turn or evolve into a higher order multi nature construct which is described earlier i.e. psychological capital. Psychological capital has been revealed to be significant for performance at both individual and as well as at group levels of analyses (Gooty, et al. 2009; Luthans et al. 2007; Walumbwa et al. 2011; Walumbwa et al. 2010). It is made obvious by Luthans (2002) that among the results and outcomes of the well-known Hawthorne studies that were carried in 1920s is the relationship among the employee performance and the positive feelings.In endorsing the contemporary book about Psychological Capital i.e. PsyCap(Luthans et al. 2007), the OB scholar named as Denise Rousseau put forth that it 
shows how contemporary revolutions in positive psychology movement can turn into benefits for the companies, managers, and finally workers. As the empirical research targeting PsyCap is still evolving, human resource managers in broad-spectrum, and exclusively those concerned with or to HRD, can be assured that at least at this particular stage of research, PsyCap is considered to have a strong, solid and significant relationship with the established desirable outcomes and especially employee performance. Although the journey of PsyCap seems off to a good beginning in the right direction and so as to reach its aspiring scientific and the practical goals, there remains an urge for more theorybuilding followed by research and effective application.It is cleared up to this point of time that the study targets the relation of psychological capital and performance. It investigated the linkage of these two in order to get further know how of the target variables but the discussion does not ends here and enter into a new paradigm and open new doors for research.

It is universally believed that 5 senses in general are found in human beings and these senses include sense of taste, hearing, touch, smell and that of sight. By making use of these senses human being in general receives a number of stimuli from the immediate surroundings. The information that is gained from immediate surrounding or surrounding world in the form of the stimuli by all humans is being processed internally and is transformed into a rational knowledge and is than employed to explore about certain matter, by making the use of emotions. This entire mechanism gives way to a novel chapter or pattern in the so called research history and has been named as emotional intelligence. For the field of research, emotional intelligence has gone ahead remarkably in developing of theoretical background. (Fiori, 2009; Joseph and Newman, 2010; Lindebaum, 2012; Mayer, Roberts, et al., 2008; Mayer, et al. 2008). A noticeable and visible amount of attraction and status is being achieved by emotional intelligence in academic and as well as popular media (Cooper and Sawaf, 1996; Davies, et al. 1998; Goleman, 1995, 1998. Psychological capital and emotional intelligence are comparatively new topics in the area of human resource management and organizational behavior. Most research regarding psychological capital and emotional intelligence has been conducted in Western countries (Luthans et al 2008). Negligible research has explored these concepts in Asian geographies specially Pakistan therefore there is a strong need to investigate this concept in Asian cultures like Pakistan. A majority of studies conducted in western countries have linked psychological capital and emotional intelligence to employee performance. However this link remains unexplored in Asian cultures particularly subcontinent region like Pakistan.

\subsection{Problem Statement}

Psychological capital and emotional intelligence are comparatively new topics in the area of human resource management and organizational behavior. Most research regarding psychological capital and emotional intelligence has been conducted in Western countries (Luthans et al 2008). Negligible research has explored these concepts in Asian geographies specially Pakistan therefore there is a strong need to investigate this concept in Asian cultures like Pakistan. A majority of studies conducted in western countries have linked psychological capital and emotional intelligence to employee performance. However this link remains unexplored in Asian cultures particularly subcontinent region like Pakistan. 


\subsection{Objectives of the Study}

This study aimed at examining the link between psychological capital emotional intelligence and employee job performance. Following were the specific objectives of this study

- To examine the relationship between psychological capital and job performance

- To investigate the relationship between emotional intelligence and job performance

- To gain insight regarding the psychological capital and emotional intelligence of individuals of the target population.

\subsection{Hypothesis of the study}

The following hypotheses were considered in the given study:

\section{Hypothesis 1}

$\mathrm{H}_{0}$ : There is no significant relationship between Psychological capital and employee's performance

$\mathrm{H}_{1}$ : There is significant relationship between Psychological capital and employee's performance

\section{Hypothesis 2}

$\mathrm{H}_{0}$ : There is no significant relationship between Emotional intelligence and employee's performance

$\mathrm{H}_{1}$ : There is significant relationship between Emotional intelligence and employee's performance.

\subsection{Significance of the Study}

For organization to be successful, high performance of its employees is a compulsory and vital instrument. Once available for the study it would assist the selection committees of the organizations to select such employees who have high level of emotional intelligence as E.I is trait like and after selection develop their psychological capital as this is state like so as to obtain high performance from them and obtain success and competitive edge in the hyper competitive world.

\section{Literature Review}

The domain of work is changing fast on a daily basis. Increasing technological change, globalization, competition, the growth of the service sector and also delivery speed, drives hand in hand with growing performance demands. To deliver exceptional performance, employees at present day are required to be far more involved in their work, which is not only of physical nature, but also of emotional and mental nature (Turner et al., 2002). For survival and retaining competitive edge, organizations are putting continuous pressure on their employees to show performance. Different variables have been considered in the past to have an impact on the overall performance of the employees. Some of the studies which have already been conducted on the subject topic are described in the following. All these studies are classified according to the individual area of interest like psychological capital, and emotional intelligence. The relationship of both the psychological capital and emotional intelligence is described in the following sections. 


\subsection{Psychological capital and Employee Performance}

According to resource based view of firm the optimal use of human capital can become a vital and key source in obtaining competitive advantage as it is a difficult task for the competitors to imitate (Barney, 1991). It is this resource-based view (RBV) which has led to significant consideration in the human resource development (HRD) field on assessing the value and effect of the human capital on the performance (e.g., Arthur, 1994; Huselid, 1995; Huselid et al., 2005). Largely encouraged by the positive psychology movement in recent times (e.g., see Seligman and Csikszentmihalyi, 2000; Sheldon and King, 2001; Snyder and Lopez, 2002), a call has been there to go beyond the human capital (which are generally familiar to be the experience, education and implicit knowledge of the human resources) by concentrating on what has been called positive "psychological capital" (Luthans and Youssef, 2004; Luthans et al., 2007). Precisely, this psychological capital is not only concerned with the questions "who you are" which means human capital but also in growing sense "who you are going to become", your "best-self" (Luthans et al., 2007). In addition to the traditional and customary use in finance and economics, the term capital also used to signify the value of human resources i.e. (human capital) along with other concepts like intellectual, social and cultural capital. The term psychological capital represents here the individual motivational tendencies that use to accrue through the positive psychological constructs for example efficacy, hope, resilience and optimism.

Psychological capital is considered to be important for performance of the employees and many researchers have focused their research on finding and exploring the relationship between psychological capital and performance of employees. Psychological capital is demonstrated to be vital for performance at individual and also group levels of analyses (Luthans et al., 2007; Gooty et al., 2009; Walumbwa et al., 2010; Walumbwa et al., 2011). A study was conducted by Luthans et al. (2005) to investigate the psychological capital of Chinese workers by exploring the relationship with performance by taking a sample of 422 respondents working at factory level. They investigated relationship of psychological capital of Chinese workers and their performance in the context of three factories (two private and one state-owned) in the People's Republic of China. Results specified that the workers' positive states of hope, optimism, and resiliency, individually and when the three were made collective into a core construct of psychological capital, significantly correlated with their performance level, as it was rated by their own supervisors. An analysis of workers in one of those factories $(n=272)$ also found a significant relationship among the workers' positive psychological capital and performance outcome of the relative merit-based salary.

Luthans et al. (2007) conducted a study to get a deep insight of relationship of psychological capital and performance of the employees. For investigating this relationship, Luthans et al, conducted two studies in order to analyze the four factors i.e. hope, resilience, optimism and self-efficacy in individual and it being a composite higher order factor predicted the satisfaction and work performance and correlation analysis was used in the study. Study 1 used 3 samples of sizes $(n=167,404,174)$ respectively from management students at midtown university at different points of time to check the stability of psychological capital questionnaire (PCQ) measures and with the help of survey they got the responses. The sample for study 2 was drawn from two sectors i.e. 
manufacturing and services with size of $(n=115,144)$. Study 1 resulted in providing psychometric support for a new and fresh survey measure designed for assessing each of these 4 facets, and also a composite factor. Study 2 resulted in significant positive relationship about the composite of these 4 facets with satisfaction and performance and furthermore it was concluded that composite factor can be used as better predictor of satisfaction and performance than the 4 individual facets.

Avey et al. (2010) also conducted a research study to investigate a relationship between the psychological capital and the resulting employee performance by making use of multiple studies and methods of data by using two samples from the large financial firms which had headquarters in Melbourne, Australia. Sample for study 1 consisted of 345 tellers with a response rate of 97 percent. Means, standard deviations and correlations showed that psychological capital is related to the performance and regression analysis also confirmed the findings. In sample 2, the sample size was 109 who were franchisee and response rate was 100 percent. The results of mean, standard deviation and correlation confirmed that psychological capital is related to performance and furthermore regression analysis also confirmed the proposed relationship. In both cases psychological capital questionnaire was used to measure the level of psychological capital of the employees at individual level and by using regression analysis financial performance data from firm and that of manager rated performance.

In the same way a meta-analysis was initiated by Fred et al. (2010) to examine the relationship between psychological capital and performance of employees. This study was conducted by making use of a sample of 79 police leaders and also their direct reports i.e. 264 police followers and this investigated the relationships of leader to that of follower psychological capital, service climate and their job performance. Hierarchical linear modeling (HLM) was used for investigating the proposed relationships. HLM results revealed that the psychological capital of the leader was positively related with the performance of the employees and (HLM) analysis also found that the psychological capital of leaders and followers interacted and positively predicted the rated performance. PCQ was used to anchor the responses of the respondents. Luthans and his co-workers have performed a considerable amount of quality work on the concept of psychological capital and in a similar study he studied this concept in a different perspective.

Luthans et al. (2010) studied that either psychological capital can be developed through training intervention also this can have resulting performance impact. For this purpose a pilot test was conducted which was aimed at PCI (PsyCap) intervention model) with a randomized control group design and the sample for the study consisted of 242 advanced management students from a large Midwestern university. A follow up study was also done to check that either the training intervention has resulted in improved performance in participating managers.

Peterson et al. (2011) studied the same relationship by conducting a longitudinal study and their related techniques for data analysis. The sample for the study was taken from large financial service organization for longitudinal study and consisted of ( $n=179$ financial advisory-type employees) for examining within-individual change inPsyCap over time and to see whether this change has some relationship with performance and the response rate as a result was $84 \%$ Statistically significant within-individual change or variation in PsyCap was revealed by Latent growth modeling and this change in PsyCap 
was related with change in performance outcomes of two types i.e. (financial performance i.e. individual sales revenue and supervisor-rated performance). This study provided the strongest support at that time for the relationship of psychological capital with performance.

PsyCap has also been taken into account by various researchers in Pakistan. (Abbas et al, 2012) tested main antecedents of perceived organizational politics and psychological capital with diverse sample of $(\mathrm{N}=231$ paired responses $)$ on job satisfaction, turnover intentions and supervisor-rated job performance in various organization of Pakistan. An examination of PsyCap having a moderating influence in the politics outcome relationship was also carried out. The results obtained provided a good support for the hypothesis that was proposed. Regression analysis was used and the results obtained provided evidence for the idea of perceived politics being disadvantageous for the desired outcomes at the workplace. It was further evident that PsyCap has a positive influence on the desired outcomes including job performance and job satisfaction and not on the turnover intention.

\subsection{Emotional Intelligence}

Besides the role of psychological capital in affecting the performance of employees, emotional intelligence is also an important variable that effect performance. In the last fifteen years, there are enough materials written about emotional intelligence (E.I) and its role at the workplace. The E.I experts have put forward different definitions and models for emotional intelligence in order to understand E.I as a concept and also to study the impact it is having on the work and life of employees and managers. According to Daniel Goleman (1995) emotional intelligence is the capacity which recognizes the capability of one's own self and also of others to motivate our self and manage our self within our self and also in our associations (Ashkanasy et al., 2000.The complex scenario that is faced by the organizations of present day puts continuous pressure on these organizations to manage the waves of change in a way that is effective.

Emotional intelligence plays a vital role in business environment to help the employees and managers to manage the dynamic change. Selection and development along with teams and organizations are the areas where emotional intelligence can be applied. Organizations have to coach its employees in order to develop their interpersonal skills and to have an effective performance on the job with other employees; organizations must coach their employees (Bar- On et al., 2007). Apart from the technical skills, the employees must also enhance their emotional skills to enhance their job productivity. In order to be successful; organizations need to develop emotional intelligence skills of the employees so that they can work effectively in organizations (Wall, 2008). Different researchers have done their efforts to find out the relationship between emotional intelligence and performance and a copious literature is available now in this relation. The main theme of our discussion is now to throw light upon the importance of emotional intelligence. For this very purpose an efforts have been made to identify all those studies which has been conducted to highlight the importance of E.I and its relationship with many other factors and the employee's performance. Some of these studies are given in the following:

Schutte et al. (1998) examined the relationship between the emotional intelligence and cognitive task performance. For this study the sample comprised of 38 
community participants whose recruitment was done from different workplaces such as medical clinics, pharmacy, university and electronic firms. Emotional intelligence was measured by 33 items questionnaire developed by Schutte and then worked on 3 sets of anagram (scrambled words). The results of the study were in the support of the proposed hypothesis that those who have high emotional intelligence would perform better on the cognitive task than those whose emotional intelligence is lower.

Behbahani (2011) investigated the relationship of emotional intelligence (E.I) with the performance of employees. He carried out the study by taking 160 managers and also employees at departments of physical education located in Shahr-e-Rey Iran. The data collection was done through emotional intelligence questionnaire and two valid questionnaires were used for this purpose. This study examined the relationship between emotional intelligence and management capabilities of managers and the results revealed that a significant relationship exists between E.I and its components (self-regulation, motivation, self-awareness, social skills and empathy) and the capabilities of employees. A research study was also conducted by Chaudry and Usman (2011) to investigate the relationship between the emotional intelligence of employees and the resulting performance. The sample consisted of 444 employees working in different privately owned organizations and they were selected conveniently for the respective study. In this study, 33 items scale was used to measure the emotional intelligence of the employees and the performance was measure through a scale consisting 16 items which measured their OCB (organizational citizenship behavior). Pearson correlation and regression analyses techniques were used to check the association and the prediction relationship among the dependent and independent variables. A moderately high correlation between E.I and performance was revealed by results and it was established that E.I scores can predict job performance and this prediction can serve as a selection tool by the HR managers.

Jofri et al. (2010) also conducted a research study to investigate the impact of emotional intelligence of employees along with the managers on performance level (job performance). The data for the sample i.e. $\mathrm{N}=155$ were collected with the help of questionnaire from the participants who were the employees and managers at educational administration of Iran. Both primary and secondary methods of data collection were used for obtaining the required information needed for the study. A simple random sampling technique was adopted to collect the primary data through a well-structured questionnaire. The performance data was measured by 360 degree appraisal method, and E.I with a questionnaire and data was being processed though descriptive statistics, t-test and correlation analysis. The findings of the study revealed that E.I has a positive impact on employee and manager's performance level.

\section{Research Methodology}

\subsection{Universe of the Study}

In the present study, the teaching staff of the public sector universities located at district Peshawar was considered as universe of the study. In total, there are 7 (HEC march 2012) public sector universities in district Peshawar. Of these, only four universities located at the greater campus were purposively selected. The purposively selected universities are: (1) The University of Agriculture (2) Islamia College University (3) University of Engineering and Technology and (4) University of Peshawar. The 
purpose behind selection of these Universities was that they are well reputed Universities amongst all the public sector Universities at Peshawar region. In such a case, the target population consists of 1136 faculty members working on various positions, was the universe of study. Total number of faculty members working at each of the public sector universities is given in Table 3.1 (Source: Registrar offices of the concerned universities).

\subsection{Sampling Design}

Sampling design provides information about the number of units to be taken from a given population and how it would be selected. Selection of appropriate sample size depends on the experimenter expertise and availability of time and financial resources. Alam (2012) conducted a research study to investigate the "human resource management policies and organizational performance in the industrial sector, Hayatabad" by taking a sample of 121 employees to achieve the required objectives. Similarly, Ali (2012) investigated the "effect of distributive and procedural justices on job satisfaction in the industrial sector" by using a sample of 120 respondents. In the same way, Alamgir (2012) considered 150 respondents to study the perception of employees regarding the organizational politics and job outcomes.

Keeping in view the time and financial constraints, an arbitrary approach was used to select a sample of 170 faculty members working in the selected public sector Universities. All these faculty members were selected randomly in order to minimize the bias. It is important to mention that a sample of 170 faculty members was taken from the selected Universities by using a proportional allocation method (Cochran, 1977). For convenience, the proportional allocation method is defined as:

Where,

= indicate the required sample size that will be randomly selected from the public sector universities.

$=$ indicate the total number of faculty members employed in the public sector universities (population size).

$=$ number of faculty members employed in the $\mathrm{i}^{\text {th }}$ public sector university.

$=$ number of faculty members to be selected from the $i^{\text {th }}$ public sector university.

The detail of faculty members to be interviewed from each of the $i^{\text {th }}$ public sector universities are provided in Table 3.1.

Table 3.1 Distribution of sample size in the selected universities

\begin{tabular}{lcc}
\hline \hline University & Total Faculty & Sampled Faculty \\
\hline \hline University of Peshawar & 424 & 63 \\
Islamia College University & 143 & 21 \\
The University of Agriculture & 293 & 44 \\
University of Engineering and Technology & 276 & 41 \\
Total & 1136 & 170 \\
\hline \hline
\end{tabular}

Source: Registrar Offices

\subsection{Theoretical framework}

Theoretical framework that was used in the present study is given in Figure 3.1. It is clear that employee's performance was taken as dependent variable while 
psychological capital and emotional intelligence were considered as independent variables for investigating the effect of independent variables on the dependent variable.

\subsection{Description of Variables}

Detailed description of variables that were used in the given study, for obtaining the required objectives, are provided in the following separate sections:

\subsubsection{Independent variables}

The present study utilized two independent variables vizpsychological capital and emotional intelligence.

\section{Psychological Capital}

It is defined as an individual's positive psychological state of progress and is described by: (1). having confidence (self-efficacy) to undertake and putting in the essential effort to be successful at challenging jobs; (2). to make a positive attribution (optimism) about getting success now and in the future also; (3). determined toward goals and, when needed, redirecting paths to goals (hope) to succeed; and (4) when surrounded by problems and hardship, sustaining and bouncing back and even beyond also (resiliency) to achieve success. Psychological capital was measured using PCQ (Psychological Capital Questionnaire) comprised of 24-items which is developed by Luthans et al. (2007). Reponses was measured by using a 5-point Likert scale.

\section{Emotional Intelligence}

John Mayer and Peter Salovey(1990) described emotional intelligence as the ability of accurately identifying and understanding one's own emotional reactions and also of others. It also includes the capability to regulate one's emotions and using them for making good decisions and to act effectively. To find the level of emotional intelligence 5-scale questioner created and developed by Schutte (1998) i.e., emotional Intelligence questionnaire (EIS) of 13 items is to be used.

\subsubsection{Dependent Variable \\ Performance}

Performance of employee means that doing the present or current job at certain level (high or low) likely measured by William and Anderson, (1984).

\subsection{Data Collection}

The present study was based upon the primary data that was collected through a welldesigned interview schedule. The interview schedule is provided in Appendix-A. Primary data was taken from the teaching staff (all faculty members) of the selected universities, as mentioned in Table 3.1.

\subsection{Data Analysis}

The collected data was analyzed through statistical package for social sciences (SPSS) v. 20. The results are provided in terms of counts and percentages. In order to investigate the effect of psychological capital and emotional intelligence on the employee's performance, a well-known regression analysis technique was applied. For convenience, the regression model is defined as:

Where,

$$
\mathrm{EP}=\beta_{0}+\beta_{1} \text { PsyCap }+\beta_{2} \mathrm{EI}+\mathrm{e}
$$

$\mathrm{Y}=$ employee's performance 
$\mathrm{X}_{1}=$ Psychological capital

$\mathrm{X}_{2}=$ Emotional intelligence $(\mathrm{EI})$

are called the model parameters and will be estimated from the sampled data by using ordinary least square (OLS) method.

$=$ is the residual term and assumed to follow a normal distribution with zero mean and constant variance i.e. .

. It is prerequisite, that before running the OLS method, some of the important assumptions like multicollinearity and hetroscadasticitywere examined and suitable test was applied, if any in the data, as remedy.

Similarly, in order to check the association between any of the two attributes, a Chisquare test was applied. For convenience, the Chi-square test is defined as:

\section{(3.4)}

The test mentioned in equation (3.4), under the null hypothesis ( $\mathrm{Ho}$ ) follow a Chi-square distribution with $(r--1)(c--1)$ degrees of freedom. In equation (3.4), $O_{i j}$ and $e_{i j}$ indicates the observed expected frequencies, respectively.

\section{Results and Discussion}

\subsection{Measures of Cronbach's Alpha}

To check the reliability of the data that has been collected, coefficient of Cronbach's alpha was calculated and the results are presented in Table 4.1. It is apparent that variables of the study such as psychological capital, emotional intelligence and job performance have reliable and greater than 0.70 , hence the results for these attributes are reliable (Cronbach, 1951). Grounded on these results it is anticipated that the collected data describing the employee's perception regarding psychological capital, emotional intelligence and performance as well may provide enough information about the objectives under the study.

Table 4.1 Reliability Coefficients of the Studied Attributes

\begin{tabular}{lll}
\hline \hline Attribute & Cronbach's alpha & Remarks* \\
\hline \hline Psychological capital & 0.885 & Reliable \\
Emotional intelligence & 0.773 & Reliable \\
Performance & 0.71 & Reliable \\
\hline \hline
\end{tabular}

* Any attribute that has Cronbach's alpha more than 0.70 is reliable

4.5 Summary of psychological capital, emotional intelligence and employee performance

Table 4.5 indicates the MAS values (on overall basis) of the perception of employees regarding psychological capital, emotional intelligence and employee's performance. It is evident that for all the three attributes, the value of MAS is greater than 3 showing the positive perception and agreement of the sampled respondents. 
Table 4.5 Average of the employee's perception of psychological capital, emotional intelligence and employee performance

\begin{tabular}{lc}
\hline \hline Variables & Mean average score (MAS) \\
\hline \hline Psychological capital & 3.46 \\
Emotional intelligence & 3.66 \\
Performance & 3.28 \\
\hline \hline
\end{tabular}

Table 4.6.1 indicates the results of bivariate coefficient of correlation along with their respective p-values. It is evident that all the coefficient of correlations is positive indicating positive relationship between any of the two variables. In addition, the p-value for each pair is less than $5 \%$ level of significance indicating significant correlation between the two variables under study. It is important to mention that the correlation between psychological capital and emotional intelligence (which are used as independent variables in the regression model) is 0.764 which is less than 0.80 suggesting that there is no severe problem of multicolinearity in the data, and hence the estimates of model parameters (Table 4.6) will be efficient and may provide good results. Based on the results obtained, it is concluded that the regression model describing the effect of psychological capital and emotional intelligence of the employee's performance will not sufferer from the problem of multicollinearity.

Table 4.6.1 Bivariate correlation analysis

\begin{tabular}{|c|c|c|c|c|}
\hline Variable & --------- & $\begin{array}{c}\text { Psychological } \\
\text { capital }\end{array}$ & $\begin{array}{c}\text { Emotional } \\
\text { Intelligence }\end{array}$ & $\begin{array}{c}\text { Employees } \\
\text { performance }\end{array}$ \\
\hline \multirow[t]{2}{*}{ Psychological capital } & $\begin{array}{l}\text { Pearson } \\
\text { Correlation }\end{array}$ & \multirow[t]{2}{*}{1} & $0.764^{* *}$ & $0.357^{* *}$ \\
\hline & Sig. (2-tailed) & & 0.000 & 0.000 \\
\hline \multirow[t]{2}{*}{ Emotional Intelligence } & $\begin{array}{l}\text { Pearson } \\
\text { Correlation }\end{array}$ & $0.764^{* *}$ & \multirow[t]{2}{*}{1} & $0.338^{* *}$ \\
\hline & Sig. (2-tailed) & 0.000 & & 0.000 \\
\hline \multirow[t]{2}{*}{$\begin{array}{l}\text { Employees } \\
\text { performance }\end{array}$} & $\begin{array}{l}\text { Pearson } \\
\text { Correlation }\end{array}$ & $0.357^{* *}$ & $0.338^{* *}$ & \multirow[t]{2}{*}{1} \\
\hline & Sig. (2-tailed) & 0.000 & 0.000 & \\
\hline
\end{tabular}

**. Correlation is significant at the 0.01 level (2-tailed).

\subsection{Effect of psychological capital and emotional intelligence on employee performance}

In order to find out the effect of psychological capital and emotional intelligence on employee performance, regression analysis was conducted. The analysis of variance (ANOVA) of regression analysis (Appendix-B; Table B1) indicates that the p-value of Fratio is 0.000 suggesting that the model is overall significant at $1 \%$ level of significance. It is concluded that the model fit the data well and it is expected that significant effect of any of the psychological capital or emotional intelligence, or both can be obtained affecting the employee's performance. In addition, the value of $\mathrm{R}^{2}=0.109$ suggests that $10.9 \%$ variation in the employees performance has been explained by the psychological capital and for emotional intelligence the value of $\mathrm{R}^{2}=0.114$ suggesting that $11.4 \%$ of 
variation in employee performance is explained by emotional intelligence. As the value of $\mathrm{R}^{2}$ is low but it is common in cross sectional studies (Gujarati, 2003) but the overall the F-ratio is significant.

Table 4.6 displays the results of regression coefficients of psychological capital and emotional intelligence along with their respective t-ratios and p-values. The positive sign of the regression coefficient of psychological capital $(B=0.330)$ reflects that a positive relationship exists in psychological capital and the employee performance. This suggests that high Psychological capital of employees may results in their higher job performance. In addition, the p-value of the t-ratio for psychological capital is less than $5 \%$ level of probability suggesting a significant positive relationship between the psychological capital and the employee's job performance.Mohammad Abbas conducted a research on impact of psychological capital on innovative job performance and job stress and found a significant relationship between psychological capital and performance.Moreover, the positive sign of the regression coefficient for emotional intelligence $(\mathrm{B}=0.338)$ also shows that there exists a positive relation between the emotional intelligence and employee performance. The results suggest that for increased level of Emotional intelligence results in increased level of job performance. Moreover, the $\mathrm{p}$-value for $\mathrm{t}$ value of emotional intelligence is less than $5 \%$ i.e. 0.000 , hence suggesting a positive significant relationship between emotional intelligence and employee's job performance.Anjali Ahuja (2011) conducted a research on impact of emotional intelligence on performance of call center employees and found a positive and significant relationship between emotional intelligence and employee performance.

Table 4.6 Effect of psychological capital and EI on employee performance Employee performance

\begin{tabular}{llllll}
\hline \hline & $\beta$ & R2 & t-ratio & F-value & P-value \\
\hline \hline PsyCap & .330 & .109 & 4.535 & 20.564 & .000 \\
Emotional & .338 & .114 & 4.655 & 21.667 & .000 \\
Intelligence & & & & & \\
\hline \hline
\end{tabular}

\section{Summary}

This study was carried out to explore the effect of psychological capital and emotional intelligence on performance of employees. For obtaining the objectives of the study primary data was utilized. This primary data was obtained through adopted questionnaire. Questionnaires about the required variables were distributed among the employees (faculty) ( $n=170)$ of 4 public sector universities of Peshawar. To measure all the variables, likert scale of 5 points was used. The demographic data of was also considered in the research. In order to check the reliability of data Cronbach Alpha coefficient was computed. For all the selected variables the results were shown in the form of counts and percentages. These variables included psychological capital, emotional intelligence and employee performance. For finding the figures for employees perception (MAS) was calculated. Association between the variables was obtained by applying a Chi square test with $5 \%$ level of significance.

The value of Cronbach alpha for two of the attributes i.e. psychological capital and emotional intelligence is higher than $70 \%$ that falls in reliable zone. However the 
value of Cronbach alpha for employee performance was less than $70 \%$ and the results for this variable are not reliable even after the deletion of items. The overall reliability value is greater than $70 \%$ which means that data collected from the faculty of public sector universities is reliable and may provide detailed estimates about the perception of employees about different attributes like psychological capital, emotional intelligence and employee performance. In a similar way it was found that (MAS) for the majority of variables is greater than 3 indicating that the independent and dependent variables are related to each other. However, for total 6 attributes the MAS value is less than 3 which shows neutral attitude or disagreement of the respondents on these attributes. Chi square test with 5\% level of significance results revealed that the independent variables i.e. psychological capital and emotional intelligence has a positive effect on dependent variable i.e. employee performance. This shows that the employees having high level of psychological capital and emotional intelligence will show a high level of performance. Regression analysis was performed in order to ascertain the effect of psychological capital and emotional intelligence on employee performance individually. The results obtained made it obvious that the model overall is significant i.e. the $\mathrm{F}$ value is $13.2 \%$ at $5 \%$ level of significance. $\mathrm{R}$ square value shows that $13.27 \%$ variation in employee performance is shown by psychological capital and emotional intelligence. The positive sign of coefficients of psychological capital and emotional intelligence specifies that they have a significant positive effect on employee performance.

\subsection{Conclusion}

The study was conducted in the public sector universities of Peshawar university campus in order to find the effect of psychological capital and emotional intelligence on employee performance. From the overall study it is shown that there is significant positive association between psychological capital and emotional intelligence with employee performance. The results of the study clearly depicts that performance of the employees depends on the above mentioned variables. This study provides guidelines to the selection committees to select the employees with high level of psychological capital and emotional intelligence in order to get high performance of employees ultimately resulting in the success of organization. The study in hand concludes that management should pay attention to selection process because selecting the best candidates is the key to taking the organization on the roads of success. Moreover the findings of the study will assist universities and other organizations to perform superior than ever before by understanding and giving attention to both psychological capital and emotional intelligence.

\subsection{Recommendations}

Grounded on the findings of the study, the subsequent recommendations are advanced:

- Psychological capital and emotional intelligence have direct effect on employee performance along with having practical role in the progress of the employees. Because of having such important role the organization should focus on these factors in order to enhance their performance.

- Managers should give attention to building along with strengthening the psychological capital of their employees as there are particular guidelines and copious successful uses in the positive psychological literature for improving the hope, optimism, resilience and psychological capital. 
- Researchers have urged that authentic leadership can heighten the psychological capital in one's organization to increase performance and competitive advantage. Based on this theory authentic leaders can offer opportunities to construct their own psychological capital and that of their subordinates.

- As psychological capital is considered to be open to human resource development so managers can invest in, build and hence improve psychological capital by encouraging learning among employees.

- It is also evident from theory and research that the emotional intelligence of employees can be enhanced by training and development techniques like 360degreeand coaching. So in order to improve the emotional intelligence of employees, managers should pay attention to effective trainings so that the organizations may attain success in the long run.

- The organizations should improve the reward system which if coupled with selection of employees having high level of psychological capital and emotional intelligence will result in the high performance of employees.

\section{References}

Arthur, J. B. (1994). Effects of Human Resource systEms on Manufacturing Performance and Turnover. Academy of Management Journal, 37: 670-687.

Ashkanasy, N. M., E. J.Charmine \&d W. J. Z. Härtel, (2000). Emotions in the workplace:

Avey, J., B. L. Nimnicht \& N. G. Pigeon. (2010). Two field Studies Examining the Association Between Positive Psychological Capital and employee Performance. Leadership and Organization Development Journal, Vol. 31(5), pp. 384-401.

Barney, J. (1991). Firm Resources and Competitive Advantage. Journal of Management, 17, 99-120.

Bar-On, R., Maree. J. G. \& Maurice, J. E. (2007). Educating People to be Emotionally Intelligent, ( $1^{\text {st }}$ ed.). United Kingdom: Greenwood Publishing Group, (chapter 3).

Behbahani, A. A. (2011). A Comparative Study of the Relation Between Emotional Intelligence and Employee's Performance. Procedia - Social and Behavioral Sciences, 30, $386-389$

Chaudhry. A. A. \& Usman, A. (2011). An investigation of the relationship between employees' emotional intelligence and performance. African Journal of Business Management, 5(9), 3556-3562.

Cherniss, C. (2000). Emotional Intelligence: what is it and why it matters. Paper presented at the Annual Meeting of the Society for Industrial and Organizational Psychology. New Orleans, LA.

Cooper, R. K \& Sawaf, A. (1996). Executive EQ Emotional Intelligence in Leadership and Organizations.Newyork: Peegiree Books.

Davies, M., Stankov, L., \& Roberts, R. D. (1998). Emotional intelligence: In search of an elusive construct. Journal of Personality and Social Psychology, 75, 989-1015.

Fiori, M. (2009). A new look at emotional intelligence: A dual process framework. Personality and Social Psychology Review, 13(1), 21-44. 
Fred, O. W., Peterson, S. J. Avolio, J. B. \& Hartnell, C. A. (2010). An Investigation of the Relationships Among Leader and Follower Psychological Capital, Service Climate, and Job Performance. Personnel Psychology, 63: 937-963.

Goleman, D. (1995).Emotional Intelligence. (1st ed.) New York: Bantam. (Chapter 1).

Gooty, J., M. Gavin., P. D. Johnson., M. L. Frazier \& D. B. Snow. (2009). In the eyes of the beholder: Transformational leadership, positive psychological capital, and performance. Journal of Leadership and Organizational Studies, 15: 353367.

Hedges, C. (2009).The Illusion of Happiness. In C. Hedges (Ed.).Empire of illusion: The end of literacy and the triumph of spectacle (pp. 115-139).New York, NY: Nation Books.

Huselid, M. A. (1995). The impact of human resource management practices on turnover, productivity, and corporate financial performance. Academy of Management Journal, 38, 635-672.

Huselid, M. A., B. E. Becker. \& R. W. Beatty. (2005). The workforce scorecard: Managing human capital to execute strategy. Boston: Harvard Business School Press.

Jorfi1. S. H., Jorfi, S. \& Moghadam, S. K. (2010). Impact of Emotional Intelligence on

Kersting, K. (2003). Turning Happiness Into Economic Power.Monitor on Psychology, 34(11), 26.

Lindebaum, D. (2012). I rebel - therefore we exist: emotional standardization in organizations and the emotionally intelligent individual. Journal of Management Inquiry, 21(3), 262-277.

Luthans, F. \& Youssef, C. M. (2007). Emerging positive organizational behavior. Journal of Management, 33, 321-349.

Luthans, F. \& Youssef, C. M. (2004). Human, social, and now positive psychological capital management. Organizational Dynamic,33, 143-160.

Luthans, F. (2002). Positive Organizational Behavior: Developing and Managing Psychological Strengths. Academy of Management Executive, 16(1), 57-72.

Luthans, F. (2002). Positive organizational behavior: Developing and managing psychological strengths. Academy of Management Executive, 16, 57-72.

Luthans, F. (2002). The Need for and Meaning of Positive Organizational Behavior. Journal of Organizational Behavior, 23, 695-706.

Luthans, F. (2002b). Positive Organizational Behavior: Developing and Managing Psychological Strengths. Academy of Management Executive, 16(1), 57-72.

Luthans, F., Avey, J. B. Avolio, B. J. \& Peterson, S. J. (2010).The Development and resulting performance impact of positive psychological capital. Human Resource Development Quarterly, 21(1), 41-67.

Luthans, F., Avolio, B. J. Avey, J. B. \& Norman, S. M. 2007. Psychological capital: Measurement and Relationship with Performance and job Satisfaction. Personnel Psychology, 60, 541-572.

Luthans, F., Avolio, B. J. Avey, J. B. \& Norman, S. M. (2007). Positive Psychological capital: Measurement and relationship with Performance and Satisfaction. Personnel Psychology, 60, 541-572. 
Luthans, F., B. J. Avolio, F. O. Walumbwa and W. Li. 2005. The psychological capital of Chinese workers: exploring the relationship with performance. Management and Organization Review, 1(2), 249-271.

Luthans, F., Youssef, C. M. \& Avolio, B. J. (2007). Psychological capital: Developing the human competitive edge. Oxford, UK: Oxford University Press.

Lyubomirsky, S., King, L.\& Diener, E. (2005). The benefits of frequent positive affect: Does happiness lead to success? Psychological Bulletin, 131, 803-855.

Mayer, J. D., Roberts, R. D. \& Barsade, S. G. (2008). Human abilities: Emotional intelligence. Annual Review of Psychology, 59, 507-536.

Mayer, J. D., Salovey, P. \& Caruso, D. R. (2008). Emotional intelligence: New ability or eclectic traits? American Psychologist, 63(6): 503-517.

Nelson, D., \& Cooper, C. L. (Eds.) 2007.Positive organizational behavior: Accentuating the positive at work. Thousand Oaks, CA: Sage.

Performance of Employees. Postmodern Openings, Year 1, Vol.4,(4).

Peterson, J. S., Carey, W. P., Luthans, F. Avolio, B. J., Walumbwa, F. O. \& Zhang, Z. (2011). Psychological capital and employee performance: a latent growth modeling approach. Personnel Psychology, 64, 427-450.

Psychologist, 55: 5-14.

research, Theory, and Practice, (1st ed.). United Kingdom: Greenwood Publishing Group, (Chapter 4).

Schutte, N. S., Malouff, J. M., Hall, L. E., Haggerty, D. J., Cooper, J. T., Golden, C.J. \& Dornheim, L. (1998). Development and Validation of a Measure of Emotional Intelligence, Personality and Individual Differences, 25,, 167-177.

Schutte. N. S., Schuettpelz , E. \& Malouff, J. M. (1998) . Emotional Intelligence and Task Performance. Imagination, Cognition, and Personality, Baywood publishing 20: 347-354.

Seligman, M. E. P. and M. Csikszentmihalyi. 2000. Positive psychology. American

Sheldon, K., King, L. (2001). Why positive psychology is necessary. American Psychologist, 56, 216-217.

Snyder, C. R. \& Lopez, S. (2002). Handbook of positive psychology. Oxford, United Kingdom: Oxford University Press.

Sy.T., Tram, S. \& O’Hara, L. A. (2006). Relation of Employee and Manager Emotional Intelligence to job Satisfaction and Performance. Journal of Vocational Behavior, 68, 461-473.

Turner, N., Barling, J. \& Zacharatos, A. (2002). Positive psychology at work. In C.R. Snyder S.J. Lopez (Eds.).Handbook of positive psychology (pp. 715-728). Oxford, UK: Oxford University Press.

Wall, B. (2008).Working Relationships using Emotional Intelligence to Enhance your Effectiveness with Others (1st Ed.) USA: Davies Black Publishing, (Chapter2).

Walumbwa, F. O., Luthans, F. J., Avey, B. \& Oke, A. (2011). Authentically leading groups: The mediating role of positivity and trust. Journal of Organizational Behavior, 32, 4-24. 
Walumbwa, F. O., Peterson, S. J., Avolio, B. J. \& Hartnell, C. A. (2010). An investigation of the relationships among leader and follower psychological capital, service climate, and job performance. Personnel Psychology, 63, 937-963.

Wright, T. A. (2003). Positive organizational behavior: An idea whose time has truly come. Journal of Organizational Behavior, 24, 437-442. 